\title{
Development of educational kit for IoT online learning
}

\author{
Nurulhuda Abdul Rahman ${ }^{1}$, Muhammad Ridzuan Idris ${ }^{1}$, Irdayanti Mat Nashir ${ }^{2}$ \\ ${ }^{1}$ Department of Electrical, Politeknik Sultan Mizan Zainal Abidin, Terengganu, Malaysia \\ ${ }^{2}$ Faculty of Technical and Vocational, Universiti Pendidikan Sultan Idris, Perak, Malaysia
}

\section{Article Info}

\section{Article history:}

Received Sep 20th, 2020

Revised Oct 18th, 2020

Accepted Oct 21th, 2020

\section{Keyword:}

Internet of Things (IoT)

Online Learning, Learning from

Home

Training Kits, Training Module

Educational Kit

Modern Learning Design

Future Learning

\begin{abstract}
Internet of Thing (IoT) is one of the elements that drive the development of the Industrial Revolution (IR 4.0). Therefore, IoT has become the most important agenda in the globalization era including the field of education. The IoT element has been widely engaged in higher education syllabus. However, in COVID 19 pandemic, the teaching and learning process for IoT becomes more challenging and difficult to deliver. As a solution, the Educational Kit for IoT Online Learning has been developed. This online learning kit will help students to practically learn the IoT without a face to face lecture. The objectives of the paper are to provide an overview of existing IoT education solutions and to develop IoT online learning kit. This learning kit consists of IoT development hardware and software which are equipped with a camera that connected to the online conference software. This paper will explain the development of the kit. Compared to other kits, this learning kit can directly be used for online learning and helps students to practice IoT at home, especially during a pandemic. On the other hand, IoT Online Kits is a pioneer in higher education for practical online learning.
\end{abstract}

(C) 2020 The Authors. Published by IICET.

This is an open access article under the CC BY-NC-SA license

(https://creativecommons.org/licenses/by-nc-sa/4.0

\section{Corresponding Author:}

Muhammad Ridzuan Idris,

Electrical Department, Politeknik Sultan Mizan Zainal Abidin, Dungun, Terengganu, Malaysia

Email:ridzuan.phd@gmail.com

\section{Introduction}

Internet of Things (IoT) is a technological revolution that represents the future of computing and communication(Madakam et al., 2015). Day by day, the application of IoT has been widely used in our daily life. For example, smart home, smart building, internet of medical things, smart grid et cetera. IoT is an element that can encourage the industrial revolution 4.0 to be achieved. Besides, it can bloom and bring a high impact on the economy. With this, we will be in line with the developed country in the term of technology. Since then, the science of IoT should be emphasized.

Realizing the importance of IoT, it has been taught at school and embedded into the syllabus, especially in tertiary level. However, to implement the curriculum of IoT, teachers need the skills and expertise to handle the development of IoT. Most of the teachers and lecturers have developed their training kit special for IoT learning. Some of them has developed training kit, training module and IoT trainer. The basic of IoT trainer or kit consists of a microprocessor, sensor as input and the output of IoT. When it comes to face-to-face learning mode, teaching IoT is possible since it is tangible. However, since pandemic COVID 19 has hit the 
world, IoT learning needs to be run online. It is due to the new norm of working or studying from home which can stop the spreading of COVID 19.

Online learning has become a routine since pandemic COVID 19 hit the world. According to World Economic Forum, the COVID 19 has resulted in schools shut all across the world. With this sudden shift away from the classroom in many parts of the globe, some are wondering on how to make learning possible to almost 1.2 billion children in all over 186 countries. Coincide with the encouragement of online learning due to the Industrial Revolution (IR 4.0), online learning has been increasingly applied during this pandemic. But, the question is, is online learning can be apply to IoT course? Hence, as an alternative, an educational kit for IoT online learning should be developed.

The objectives of the paper are to provide an overview of existing IoT education solutions and to develop proposals for IoT online learning. The study draws analysis of current educational IoT environments and educational products for students. This paper describes an effort to design and build a compact portable IoT package that teaches basic I / $\mathrm{O}$ devices and examines the kit and instructional support materials produced for online learning. The kit is composed of (1) a microcontroller board, (2) an I / O interface for plug and play, and (3) software. The microcontroller module includes an Arduino Wemos and power supply unit.

Most of researcher and innovator develop training kits to make the technical and practical learning easier for the students. Hacker (2009), Junior et al. (2013), Hamid et al., (2020), Theint \& Tun, (2014) and Khaing et al. (2018) do research and innovation about the development of training kits for education purpose. While, Somantri et al. (2019), Lyzhin et al., (2019) and Kusmin et al., (2018) studied the development and the implementation of IoT training. Getuno et al. (2015), Kusuma \& Kasi Viswanath (2018) and Weyten et al. (2009) create the training module with online learning element. Based on the review, most of them develop training kit suit for face-to-face learning. And rarely develop training kit equipped with online learning components. On top of that, research on training kit with online learning mode must be emphasized to encourage students learning especially during pandemic.

\section{Hardware Implementation*}

IoT Online Kits hardware is divided into four part which are microcontroller and breadboard as the main part, sensor and relay part, traffic light part and motor speed control part. Microcontroller part is the main part of this training kit. The function of this part is as a 'brain' of the training kit which controlled the entire hardware. The microcontroller used for this training kit is Arduino Wemos. This Arduino Wemos use Atmega328P as for microprocessor. Arduino Wemos itself already has a built-in wi-fi ESP8266 system which can connect to the Internet directly. The data read by the processor can directly send to the internet cloud.

The second part of this system is the sensor and relay. The sensors are among the most essential parts of your IoT learning. Two sensors that are used are DHT11 types that can measure environments humidity and temperature and IR sensor which can detect a non-transparent object. Data from these sensors will be sent to the microcontroller for processing and subsequently delivered to the internet cloud. Relay is one of the components, where it is used as a connector for different types of external power supply. The relay section will be used if connected if the instructor or student would like to see the use of IoT applications in the real world. For example, IoT training kits can control fans or lights at home via online if it was connected with the Internet and programmed.

The third part is the Traffic Light interface section where it has 12 different colours of LED. This section will be used for basic learning of IoT. If this section is connected to the microcontroller, students or trainers are able to control led online according to the desired colour. If it fully programmed, it can implement IoT Traffic which can control the time of the traffic interval via online. The last part is the motor speed controller, where it is the output section for IoT learning. This section enables students to make demonstrations of IoT usage directly. If it programmed, instructors or students are able to control the motor speed via online. Figure 1 shows the IoT Online Training Kits Hardware. 


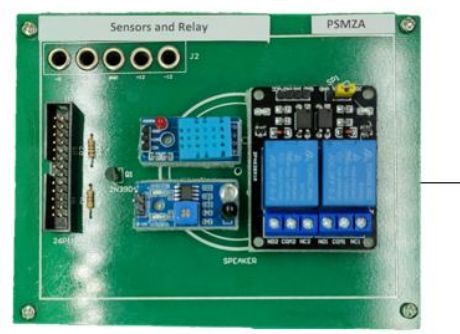

Sensors and Relay

DHT11 - Temperature and Humidity Sensor Two Channel Relay- For external circuit connection

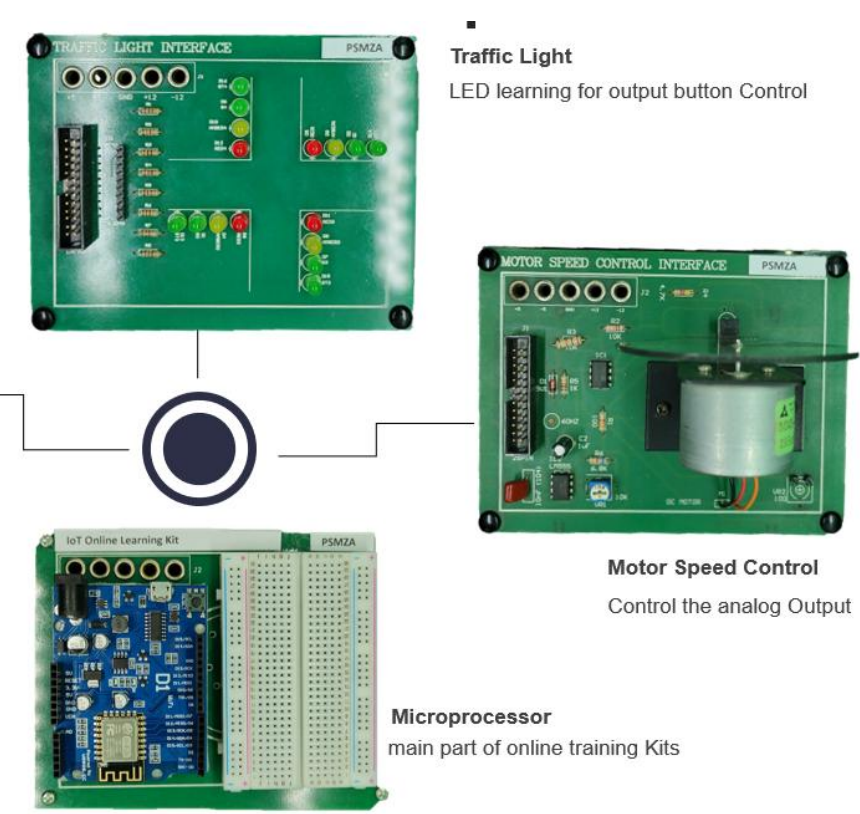

Figure $1<$ IoT Online Training Kits Hardware>

\section{Software Implementation}

Several types of software, apps and web-based applied in producing IoT online Training Kits. It is because IoT learning requires software that connects hardware, Internet cloud and users. Table 1 shows the software, application and Web base used on IoT Online Training Kits

Table 1: Software IoT Online Training Kits

\begin{tabular}{lll}
\hline Bil & Nama Software/Web-based & Penggunaan \\
\hline 1. & Arduino IDE & Interfacing between hardware and software \\
2. & hivemq.com & Websocket and cloud \\
3. & Thingspeak.com & Data Viewer \\
4. & IoTMQTT panel & Data Monitor and Control App via Smart Phone \\
$\mathbf{5 .}$ & Node-Red Dashboard & Data Monitor and Control App via Desktop \\
\hline
\end{tabular}

Arduino IDE Software is the most important software used in online IoT learning. It is a software that is an interface between hardware, web-based and apps. Instructors will teach programming IoT using this IDE software in the form of coding essential on $\mathrm{C}$ language. Coding written will determine whether data from sensors was successfully sent to the cloud or not. If the written coding is accurate and properly programmed, the data will be sent to the web socket hivemq.com and thingspeak.com. Students are able to view the data through real-time display and graph. WebSocket data from hivemq.com will be able to display and controlled via smartphone in IoTMQTT panel. The data also can be viewed via Node-Red Dashboard on the desktop computer. Figure 2 shows a full relationship between software, web-based, applications and hardware. 


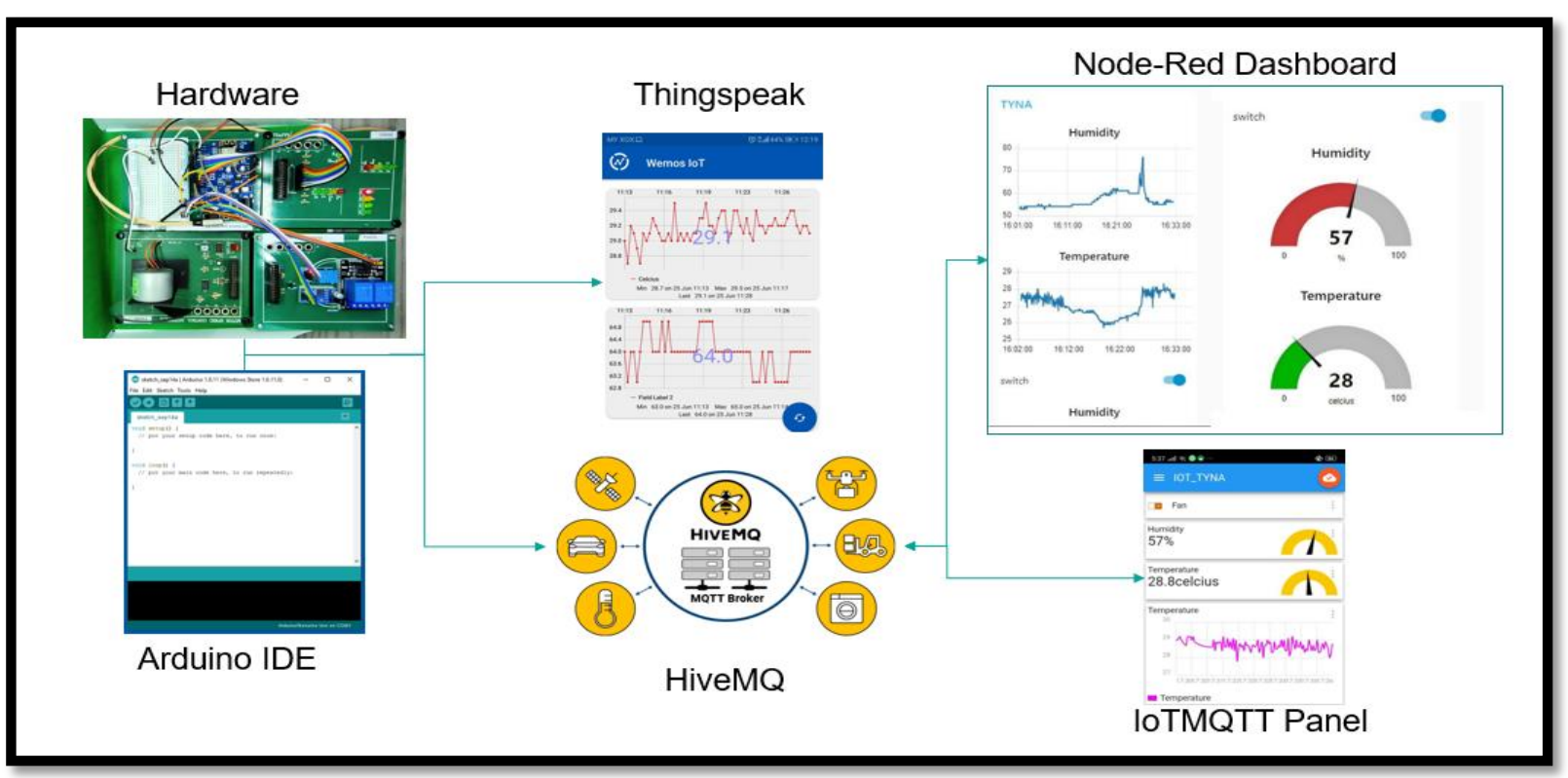

Figure $2<$ Relationship between Software, Web based, Applications and Hardware>

\section{Results and Discussion}

IoT Training Kits usually can only be used when the instructor teaches practical in face-to-face. But with the existence of pandemic COVID19, instructors are not advised to face the students. Hence, innovation has been developed to teach practical IoT via online. IoT Online Training Kits is aimed at solving the problem of difficulty in teaching practical in online mode. It became the pioneer for researcher and innovator to make a study on this matter.

Figure 3 shows the concept of using online IoT training kits. IoT Training Kits will be automatically connected to the Internet. The attached camera is intended to make demonstrations live through the conference software. By using the Conference software, the student will be able to program the IoT Training Kits via online. If the student success to program the microcontroller, data from the sensor will be sent by microcontroller to the Thingspeak Web. Data will also be sent to WebSocket HiveMQ.com to control and monitor by students. Students also can control and monitor the data via online using the Node-red Dashboard software on the desktop and IoT MQTT panel on their smartphone. Figure 4 shows a full picture of IoT online Training Kits. 


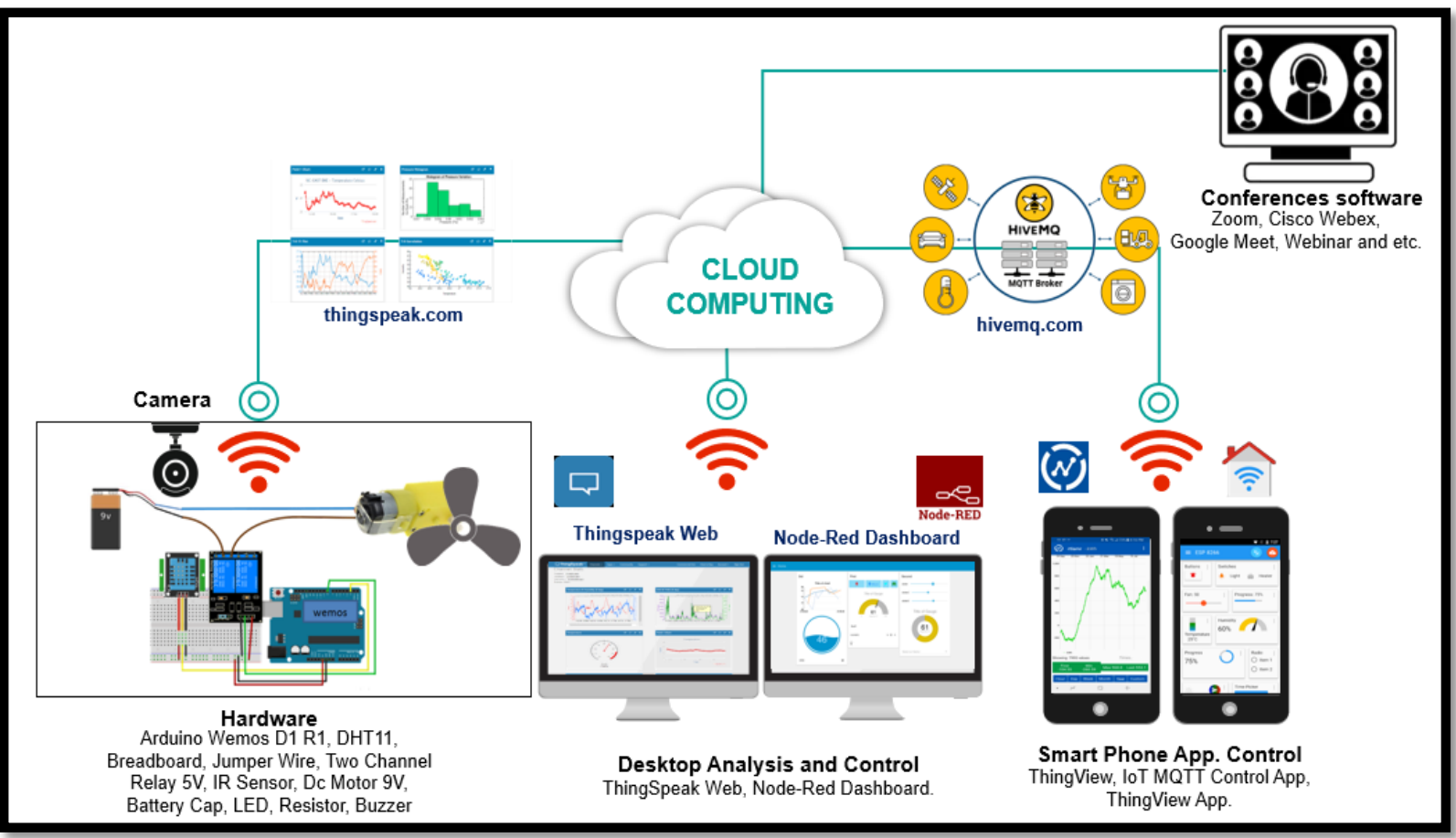

Figure 3 <Learning Concept using IoT Online Training Kits>

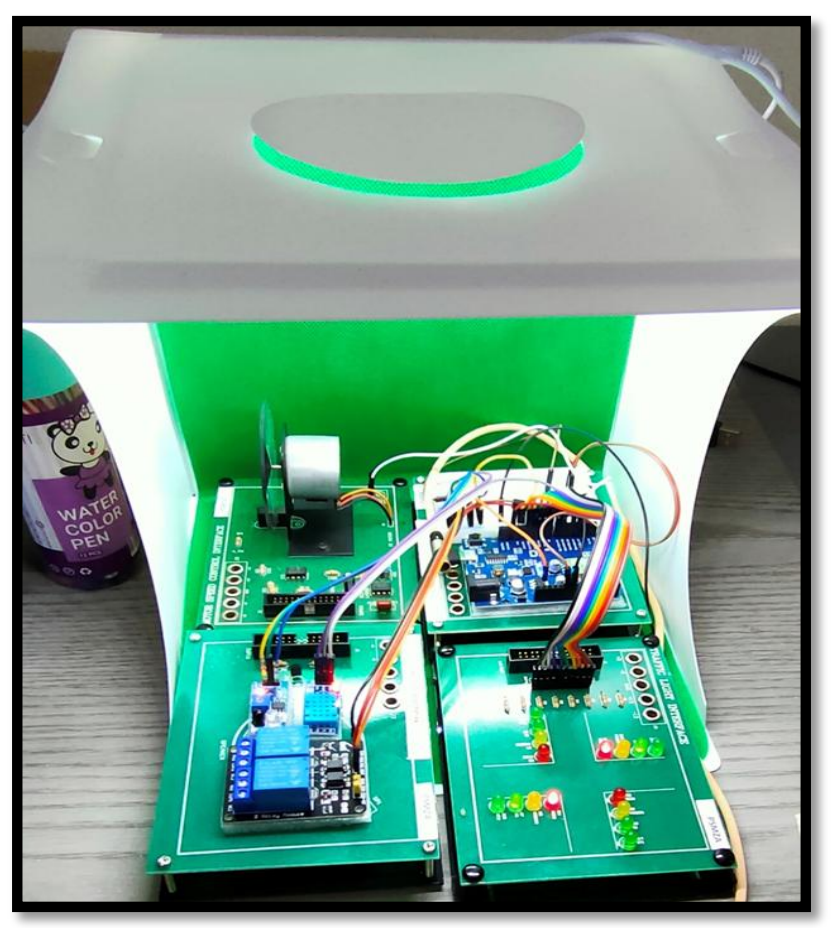

Figure 4 <IoT Online Training Kits>

\section{Conclusions}

IoT online training kits are a new option to overcome the weakness of the current conventional IoT training kits. Research and development of this subject have been conducted to promote the practical learning of online educators and students. However, this research is still in the early stages. The results of the effectiveness study 
show positive feedback and training kits are important to develop. It can also be one of the ways in which a new norm on pandemics can be established. It is expected that, with the advent of these training kits, teachers and students will have the opportunity to learn practical knowledge online.

\section{Acknowledgements}

This project is being undertaken with research being carried out in the field of experimental design for the industrial environment. The design is made with the supervision of Department of Electrical, Politeknik Sultan Mizan Zainal Abidin in collaboration with Universiti Pendidikan Sultan Idris. We would like to thank the project managers and the working colleagues for the success of this prototype device as an online training kit.

\section{References}

Getuno, D. M., Kiboss, J. K., Changeiywo, J., \& Ogola, L. B. (2015). Effects of an E-Learning Module on Students' Attitudes in an Electronics Class. Journal of Education and Practice, 6(36), 80-86.

Hacker, C. (2009). A Low Cost Student Constructed Digital Trainer Initial Design of a Student Digital Trainer. 369374.

Hamid, M. A., Permata, E., Aribowo, D., Darmawan, I. A., Nurtanto, M., \& Laraswati, S. (2020). Development of cooperative learning based electric circuit kit trainer for basic electrical and electronics practice. Journal of Physics: Conference Series, 1456(1). https://doi.org/10.1088/1742$6596 / 1456 / 1 / 012047$

Junior, L. A., Neto, O. T., Hernandez, M. F., Martins, P. S., Roger, L. L., \& Guerra, F. A. (2013). A LowCost and Simple Arduino-Based Educational Robotics Kit. Journal of Selected Areas in Robotics and Control (JSRC), 3(12), 12. http://blog.minibloq.org/

Khaing, S. W., Nopparatjamjomras, S., Nopparatjamjomras, T. R., \& Chitaree, R. (2018). Development of Arduino-based logic gate training kit. Journal of Physics: Conference Series, 1144(1). https://doi.org/10.1088/1742-6596/1144/1/012134

Kusmin, M., Saar, M., \& Laanpere, M. (2018). Smart schoolhouse-designing IoT study kits for project-based learning in STEM subjects. IEEE Global Engineering Education Conference, EDUCON, 2018-April(July), 1514-1517. https://doi.org/10.1109/EDUCON.2018.8363412

Kusuma, S., \& Kasi Viswanath, D. (2018). IOT and Big data analytics in e-Learning: A technological perspective and review. International Journal of Engineering and Technology(UAE), 7(1), 164-167. https://doi.org/10.14419/ijet.v7i1.8.11540

Lyzhin, I., Efremov, S., Rolich, A., Voskov, L., \& Abrameshin, D. (2019). Development of an Educational Kit for Learning IoT. Journal of Physics: Conference Series, 1163(1). https://doi.org/10.1088/17426596/1163/1/012015

Madakam, S., Ramaswamy, R., \& Tripathi, S. (2015). Internet of Things (IoT): A Literature Review. Journal of Computer and Communications, 03(05), 164-173. https://doi.org/10.4236/jcc.2015.35021

Somantri, Y., Wahyudin, D., Pratama, R., Nugraha, T., \& Husni, M. (2019). An affordable Internet of Things Training Kit for practical work of industrial automation. Journal of Physics: Conference Series, 1402(3). https://doi.org/10.1088/1742-6596/1402/3/033079

Theint, M. S., \& Tun, Z. (2014). Development of Digital Logic Trainer for Student's Experimentation. International Journal of Scientific Engineering and Technology Research, 03(10), 1912-1916.

Weyten, L., Rombouts, P., \& De Maeyer, J. (2009). Web-based trainer for electrical circuit analysis. IEEE Transactions on Education, 52(1), 185-189. https://doi.org/10.1109/TE.2008.924213 